\title{
Questionnaire and Intervention Study on Effects of Drinking Cows' Milk at Breakfast on the Circadian Typology and Mental Health of Japanese Infants Aged 1 - 6 Years
}

\author{
Takahiro Kawada1,2, Hitomi Takeuchi' ${ }^{1}$, Miyo Nakade ${ }^{3}$, Fujiko Tsuji, ${ }^{1,4}$, Milada Krejci ${ }^{4}$, \\ Teruki Noji ${ }^{2}$, Nozomi Taniwaki ${ }^{5}$, Tetsuo Harada ${ }^{{ }^{*}}$ \\ ${ }^{1}$ Laboratory of Environmental Physiology, Graduate School of Integrated Arts and Sciences, Kochi University, Kochi, Japan \\ ${ }^{2}$ Center for Regional Collaboration, Kochi University, Kochi, Japan \\ ${ }^{3}$ Department of Nutritional Management, Faculty of Health and Nutrition, Tokai-Gakuen University, Miyoshi, Japan \\ ${ }^{4}$ University of Physical Education and Sport PALESTRA in Prague, Prague, Czech Republic \\ ${ }^{5}$ Kindergarten Affiliated to Faculty of Education, Kochi University, Kochi, Japan \\ Email: *haratets@kochi-u.ac.jp
}

How to cite this paper: Kawada, T., Takeuchi, H., Nakade, M., Tsuji, F., Krejci, M., Noji, T., Taniwaki, N. and Harada, T. (2016) Questionnaire and Intervention Study on Effects of Drinking Cows' Milk at Breakfast on the Circadian Typology and Mental Health of Japanese Infants Aged 1 - 6 Years. Natural Science, 8, 381-396.

http://dx.doi.org/10.4236/ns.2016.89042

Received: June 13, 2016

Accepted: September 5, 2016

Published: September 8, 2016

Copyright $\odot 2016$ by authors and Scientific Research Publishing Inc. This work is licensed under the Creative Commons Attribution International License (CC BY 4.0).

http://creativecommons.org/licenses/by/4.0/ (c) (i) Open Access

\begin{abstract}
This study examines relationship between drinking cows' milk at breakfast and several mental and physical characteristics (the diurnal type, sleep habits and mental condition as anger, out of control of emotion, irritation and depression) of Japanese small children aged 1 - 6 years old. A questionnaire study and an intervention one were performed in this study. An integrated questionnaire was administered, in July 2014 to 1112 participants attending one of 10 nursery school and 1 kindergarten located in Kochi $\left(33^{\circ} \mathrm{N}, 133^{\circ} \mathrm{E}\right)$, Japan, and 582 parents (mostly mothers) which answered it instead of children (rate of answer: 51.9\%). Intervention was done to 111 children attending the kindergarten. Seventy six parents answered the questionnaire which was administered 3 months after the intervention days of 21 (rate of answer: $51.9 \%)$. There are two contents of intervention, one is the distribution of cows' milk for 21 days to be drunk at breakfast and another is the distribution of leaflet entitled "Go to bed early! Get up early! and Take nutritionally rich breakfast and cows' milk!" just before the intervention. Just before the intervention, letter was distributed to 111 parents who were asked for their children to follow the contents of the leaflet and drink the cows' milk distributed every day for the 21 days. Small children who drink cows' milk at breakfast more than once per week and take nutritionally rich breakfast more than 4 times per week are more morning-typed than the other three groups in which children fit into one or none of the two issues of taking morning cows' milk
\end{abstract}


and rich breakfast $(p<0.001)$. In this intervention study, there was positive correlation between the days when both cows' milk and main dish (protein rich resource) were taken at breakfast and the diurnal type scores three months after the intervention period of 21 days (high implementation with morning type) $(\mathrm{r}=0.416, p=$ $0.004)$. Also there was positive correlation between the implementation value for the 21 days and the diurnal type score 3 months later $(r=0.301, p=0.018)$. Drinking cows' milk at breakfast seems to be effective for small children to become more morning-typed through two sets of syntheses from tryptophan via serotonin into melatonin in the evening.

\section{Keywords}

Drinking Cows' Milk at Breakfast, Circadian Typology, Mental Health, Intervention, Japanese Infants

\section{Introduction}

\section{Breast milk and sleep health in infants}

There have been several studies on the relationship between taking breast milk and sleep health in human babies. For example, the nucleotides 5'AMP and 5'GMP in the human breast milk showed circadian rhythms, with the acrophases of the first two being during the night, and with the scotophases of the latter two during the day. While 5'UMP did not show a clear circadian rhythm, there was an increase in its levels at night. The rise in nocturnal levels of 5'AMP, 5'GMP, and 5'UMP could be involved in inducing the 'hypnotic' action of breast milk at night in the infant [1]. On the other hand, the circadian rhythms of tryptophan level were observed in the breast milk of mothers and also 6-sulfatoxymelatonin circadian rhythm of the breast-fed infants was seen [2]. Acrophase in circadian rhythm of tryptophan concentration in the breast milk occurred at around 03:00 [2]. Another circadian rhythm of the 6-sulfatoxymelatonin with the peak at 06:00 followed the rhythm of tryptophan in the infants [2]. This tryptophan intake in the infants might promote sleep of them and sleep efficiency was significantly increased in the breast fed infants compared with the formula fed infants [2].

\section{Effects of drinking cows' milk on sleep health and mental health}

What have been the studies on the effects of drinking cows' milk on the sleep and mental health of human? Already sixty years ago, adults which took a meal of cornflakes and milk were reported to exhibit a greater tendency toward uninterrupted sleep [3]. Brezinova and Oswald [4] reported that sleep of older people was shown to be improved when they fed a milk and cereal meal at bedtime by using electro-encephalography. On the other hand, the cows' milk has long been considered a relaxation beverage with sleep-inducing properties [5]. Recently Takeuchi et al. [6] reported a questionnaire study to examine the relationship between drinking cows' milk at breakfast and circadian typology in 740 Japanese infants aged $1-6$ years old. Infants who drink cows' milk at breakfast showed $21.2( \pm 3.4$ of SD) on average of Diurnal Type Scale 
Score (DTSS) which tended to be higher (more morning-typed) than $20.7( \pm 3.5)$ shown by those who did not drink cows' milk $(p=0.085)$. Infants who took carbohydrate (or carbohydrate and protein resource) plus cows' milk at breakfast were significantly more morning-typed than those who took only carbohydrate (or carbohydrate and protein resource) $(p<0.001)$. However, this study cannot discuss on the causal relationship of drinking milk to the shift to morning-typed life in the infants.

Underling mechanism as a series of synthesis from tryptophan via serotonin into melatonin in human brain

Taking tryptophan-rich foods at breakfast has been shown to be critical for people especially small children for keeping mental health and morning-typed life through serotonin and melatonin synthesis [7]-[10]. For children, cows' milk would be useful resource for taking tryptophan at breakfast, because morning at home could be very busy time and there would be only limited time for breakfast and cows' milk is very easy to drink. However, there have been no studies on whether there would be a causal relationship of drinking cows' milk at breakfast to improvement of circadian typology (shifting to morning-type), sleep health and mental health in young children. This study aims to answer the question using an intervention methodology.

\section{Participants and Methods}

\subsection{A Questionnaire Study}

An integrated questionnaire for young children and their parents (mostly mothers) was administered to 1122 small children (attending to one of 10 nursery schools and 1 kindergarten in Kochi City, $133^{\circ} \mathrm{N} 33^{\circ} \mathrm{E}$ ) aged $1-6$ years old and 582 parents (almost mothers, 51.9\%) who completed it in July (Table 1). Four hundred and sixty seven (females: 228, males: 239) answers of 582 were valuable for statistical analysis. There was more than 0.85 of r-value of Pearson's correlation value between The Diurnal Type Scale Score [11] and The Morningness-Eveningness Questionnaire Score [12] in common Japanese university students (Harada et al., unpublished).

Table 1. Fundamental data of this questionnaire study.

A.

Time of questionnaire study

Number of data
Distribution

Collection
July 2014

1221

582 (collection rate: $51.9 \%$ )

467

Valid number of answers

B.

\begin{tabular}{lcccccc} 
Sex rate of parents & Males: & 29 & $(6.2 \%)$ & Females: & 437 & $(93.8 \%)$ \\
Sex rate of children & Males: & 239 & $(51.2 \%)$ & Females: & 228 & $(48.8 \%)$ \\
Mean and SD of age & Parents: & 35.6 plus/m inus & 5.3 & Children: & 3.8 plus/minus & 1.2 \\
\hline
\end{tabular}




\subsection{An Intervention Study}

After answers to the questionnaire were collected, 111 kindergarten children were asked to follow the contents of a leaflet, entitled "Go to bed early! Get up early! Let's take a protein rich breakfast! And drink cows' milk at breakfast!" for the intervention 21 days just before which a $200 \mathrm{ml}$ cows' milk (21 bottles as vacuum backs per one child) distributed and the children were asked to drink every morning at breakfast. The integrated questionnaire was administrated to the 111 kindergarten children three months later after the 21 days intervention period. Parents of the 111 kindergarten children put the same identity numbers as secret numbers on the both questionnaires before and 3 months later the intervention. Only forty eight answers which were available for "paired-analysis" were corresponding among 3 questionnaires before and 3 months after the intervention and implementation sheet (questionnaire) (Table 2).

\subsection{The Integrated Questionnaire}

The integrated questionnaire included questions on sleep habits, meal habits, habits of drinking milk (Table 3), the diurnal type scale [11], mental health (anger and depression), and implementation sheet (7 issues: 1: "No Game Day", 2: "No TV Day", 3: "Evening lighting of orange lights with low color-temperature", 4: "Sun light exposure after breakfast", 5: "Sun light exposure early in the morning", 6: "Taking protein resources at breakfast" and 7: "Drinking cows' milk at breakfast").

Table 2. Fundamental data on number of answers in this intervention study for small children (\%).

\begin{tabular}{cccccc}
\hline & \multicolumn{2}{c}{ Males } & \multicolumn{2}{c}{ Females } & In total \\
\hline Before intervention & 48 & $(52.7)$ & 43 & $(47.3)$ & 91 \\
3 months later & 41 & $(54.7)$ & 34 & $(45.3)$ & 75 \\
Corresponding answers $1^{*}$ & 38 & $(57.6)$ & 28 & $(42.4)$ & 66 \\
Corresponding answers 2** & 26 & $(54.2)$ & 22 & $(45.8)$ & 48 \\
\hline
\end{tabular}

*Between "before" and three months "after" intervention; **Between "before" and "implementation for the 21 days".

Table 3. Questions on habits of drinking cows' milk in Japanese small children aged 1 - 6 years old.

Q1.

Does your child drink cows' milk in usual life? If so, how frequently?

A1: $\quad$ (1) $\underline{\text { Yes }}$ (1. Every day, 2. 4 - 5 times per week, 3.2 - 3 times, 4.0 - 1 time),

(2) №

Q2: $\quad$ What kind of occasion?
A2:
(1) at meals,
(2) after the exercise,
(3) after wake up,
(4) after taking bath,
(5) before going to bed,
(6) others 


\subsection{Statistic Analysis}

The data were statistically analyzed using $\chi^{2}$ test for categorized scales, Mann-Whitney U-tests and Kruskal-Wallis test for ordinal scales, Wilcoxon-test for paired analysis, and Pearson's correlation analysis using SPSS statistical software (12.0 J Windows; SPSS Inc. Chicago, IL, USA).

\subsection{Ethic Treatment}

The study followed the guidelines established by the Chronobiology International journal for the conduct of research on human subjects [13]. Before administrating the questionnaires, each participant (parents or guardians) was given a written explanation that detailed the concepts and purposes of the study and stated that their answers would be used only for academic purposes. After the above explanation, all parents (or guardians) agreed completely with the proposal. The study was also permitted by the kindergarten nurses' committees of the ten nursery schools and one kindergarten which carried out an ethical inspection of the contents of the questionnaire and detailed planning of contents of intervention which can be estimated to improve health of the children who participated in this intervention. As the young children could not complete the questionnaires themselves, their parents (mostly mothers) or guardians completed them on their behalf.

\section{Results}

\subsection{A Questionnaire Study}

Ninety five percent and 59\% of children and their mothers, respectively, had a habit to drink cows' milk (Figure 1(a)). Sixty one or seventy seven percent of children and their mothers, respectively, drank cows' milk once per day, whereas $39 \%$ and $23 \%$ of them drank it twice per day (Figure 1(b)). Forty two and thirty nine percents of children and their mothers had a habit to drunk cows' milk every day, while $27 \%$ and $35 \%$ of them drink it two or three days per week (Figure $1(\mathrm{c})$ ). More than $90 \%$ of infants took relatively small amount of cows' milk less than $100 \mathrm{ml}$ per one drinking, and about $60 \%$ of the infants took natural cows' milk (Table 4).

Table 4. I can ask a question on participants who answered "Yes" to Q 1 in Table 3. What quantity per one drinking?, what kind of cows' milk does your child drink?

\begin{tabular}{|c|c|c|c|c|c|c|c|c|c|c|}
\hline \multirow[t]{3}{*}{ A. } & \multicolumn{10}{|c|}{ What quantity per one drinking $(\mathrm{ml})$} \\
\hline & \multicolumn{2}{|c|}{ (1) $0-50$} & \multicolumn{2}{|c|}{ (2) $50-100$} & \multicolumn{2}{|c|}{ (3) $100-200$} & \multicolumn{2}{|c|}{ (4) $200-350$} & \multicolumn{2}{|c|}{$(5)>350$} \\
\hline & 96 & $(25.8)$ & 138 & $(37.1)$ & 107 & $(28.8)$ & 26 & $(7.0)$ & 5 & $(1.3)$ \\
\hline \multirow[t]{3}{*}{ B: } & \multicolumn{10}{|c|}{ What kind of cows' milk? } \\
\hline & \multicolumn{2}{|c|}{$\begin{array}{l}\text { (1) Natural with } \\
\text { no artificial control }\end{array}$} & \multicolumn{2}{|c|}{$\begin{array}{l}\text { (2) Artificial control } \\
\text { with lower fat }\end{array}$} & \multicolumn{2}{|c|}{$\begin{array}{l}\text { (3) Artificial mild } \\
\text { with higher density }\end{array}$} & \multicolumn{2}{|c|}{$\begin{array}{l}\text { (4) Artificial milk } \\
\text { with } \mathrm{Ca}^{2+} \text { or } \mathrm{Fe}^{2+}\end{array}$} & \multicolumn{2}{|c|}{ (5) Others } \\
\hline & 279 & (59.7) & 60 & (12.8) & 4 & $(0.9)$ & 56 & (12.0) & 3 & $(0.6)$ \\
\hline
\end{tabular}


Do you and your child drink cows' milk?

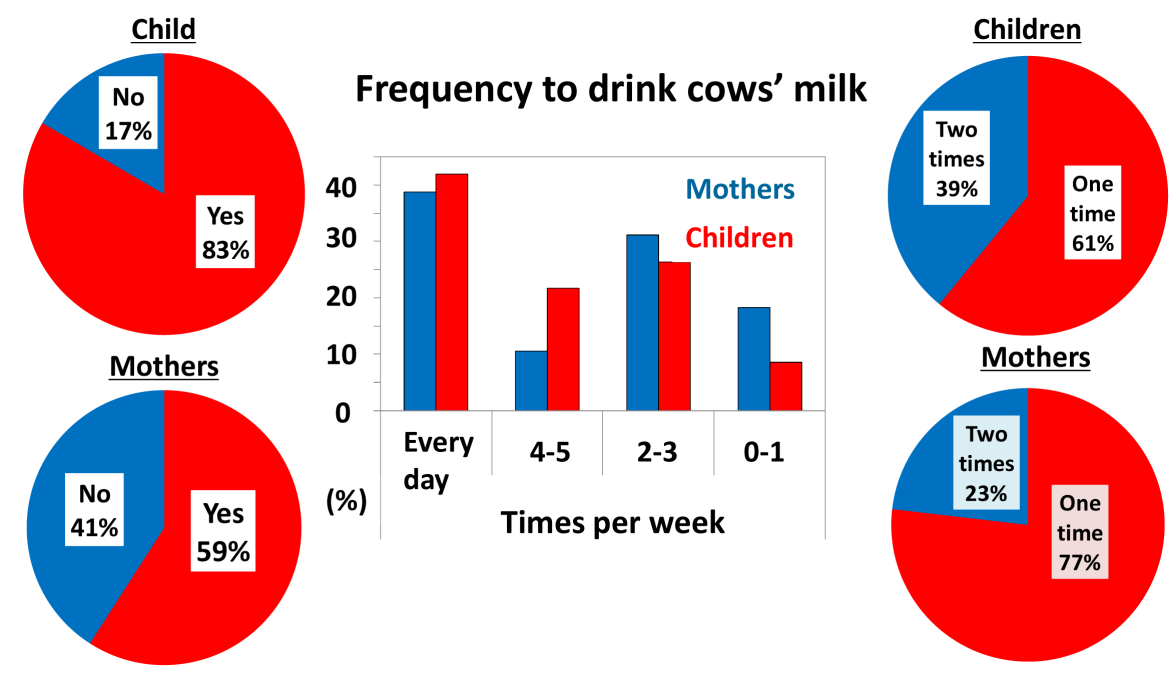

Figure 1. Fundamental data of children and their mothers on milk consumption.

Seventy one percent and $82 \%$ of children and their mothers, respectively, as drinkers had a habit to drink it in the morning of 6:00-9:00 (Figure 2(a), Figure 3(a)). Seventy one and sixty four percent of children and their mothers, respectively, as drinkers drank cows' milk at meals (Figure 2(b)). Seventy eight percent of the young children had a habit to took cows' milk and/or products made from cows' milk (Figure 3(b)). Seventy seven percent of them preferred to drink cows' milk ("relatively like", "like" or "favorite") (Figure 3(c)).

Children who had a habit to drink cows' milk are significantly more morning-typed than those who did not (Mann-Whitney U-test: $\mathrm{z}=-2.49, p=0.013$ ) (Figure 4(a)). Rate of morning-typed children in the group which drank cows' milk every day was significantly higher than that in another group which did it with lower frezuency $\left(\chi^{2}\right.$ test: $\chi^{2}$ value $=13.319, \mathrm{df}=4, p=0.01$ ) (Figure 4(b)). Children who drank cows' milk in the morning were significantly more morning typed than those who did it in the other zones of (time of) day (Kruskal Wallis test, $\chi^{2}=27.36 \mathrm{df}=4, p<0.001$ ) (Figure $5(\mathrm{a})$ ). In the group of children who drank cows' milk in the evening, children who drank it in 19:00-20:00 were more morning typed than those who drank it 18:00-19:00 or 20:00-22:00 (Kruskal Wallis test, $\chi^{2}=13.07, \mathrm{df}=3, p=0.004$ ) (Figure 5(b)).

Children who took nutritionally rich breakfast, more than 4 days per week, including carbohydrate (for example boiled rice, bread and serial), protein (for example fishes and meats) and vitamins and minerals (for example vegetables and fruits) and also had a habit to drink cows' milk were more morning-typed (Kruskal-Wallis test: $\chi^{2}$-value $=$ 45.8, $\mathrm{df}=3, p<0.001$ ) (Figure 6(a)) and showed higher quality of night sleep (Figure 6(b)) (Kruskal Wallis test, $\chi^{2}=13.91, \mathrm{df}=3, p=0.003$ ) than the other children (rich breakfast but no milk, drinking milk but poor breakfast, poor breakfast and no milk). 


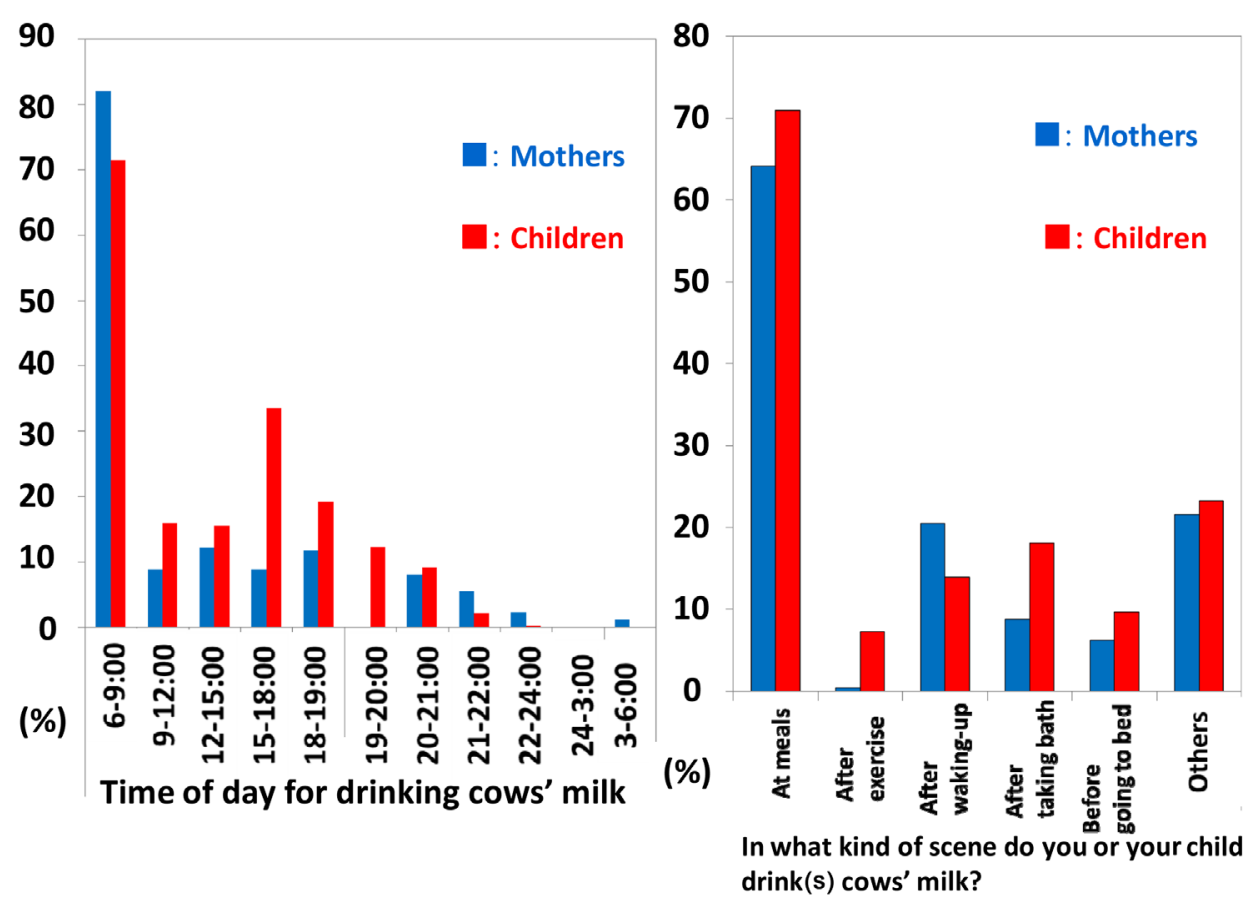

Figure 2. Time of day and what kind of cows' milk do children and their mothers drink?

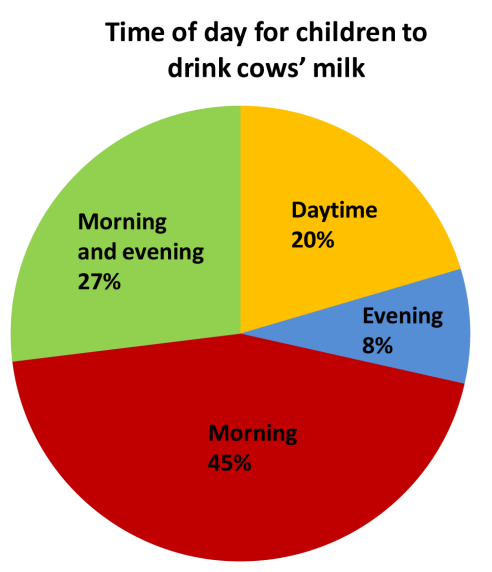

Whether does your child drink both cows' milk and also take products from milk?

\section{Frequency and time of day for drinking cows' milk (children)}

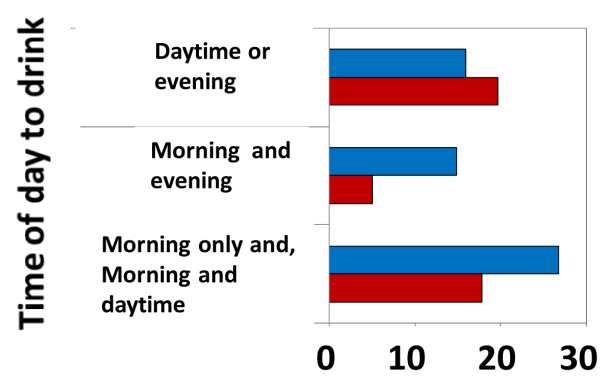

口: 0-5 days/week

: Every day

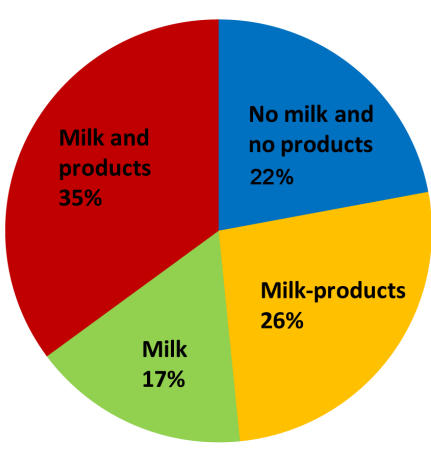

Does your child like cows' milk?

(\%)

Figure 3. Fundamental habit to drink and consume cows' milk and product from milk. 
$\left(\chi^{2}\right.$ test: $\chi^{2}$ value $\left.=13.319, \mathrm{df}=4, p=0.01\right)$

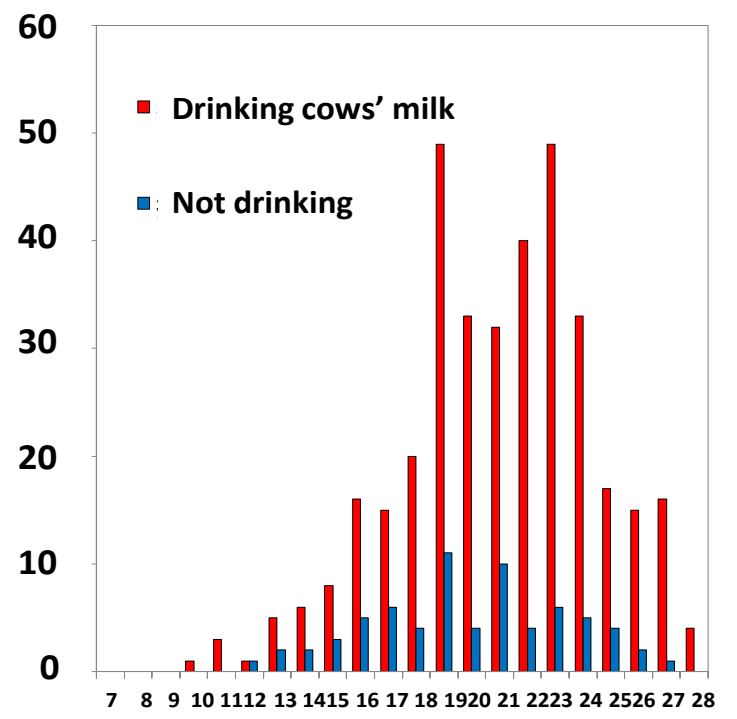

(n) The diurnal type scale

(Mann-Whitney U-test: $z=-2.49, p=0.013$ )

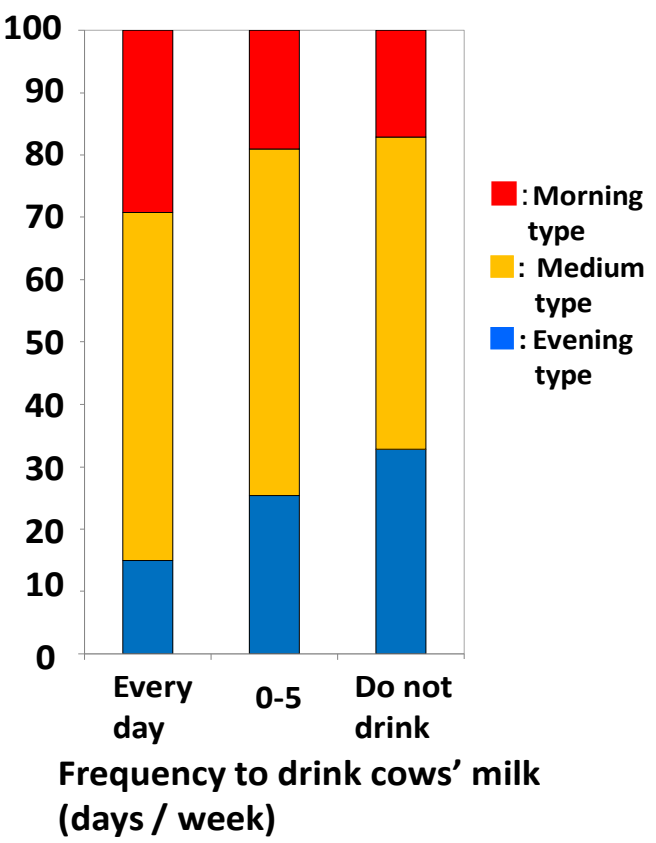

Figure 4. Relationship between the frequency to drink cows' milk and circadian typology in Japanese small children aged 1 - 6 years.

(Kruskal Wallis test, $\chi^{2}=27.36, \mathrm{df}=4, \mathrm{p}<0.001$ )

(Kruskal Wallis test, $\chi^{2}=13.07, \mathrm{df}=3, \mathrm{p}=0.004$ )
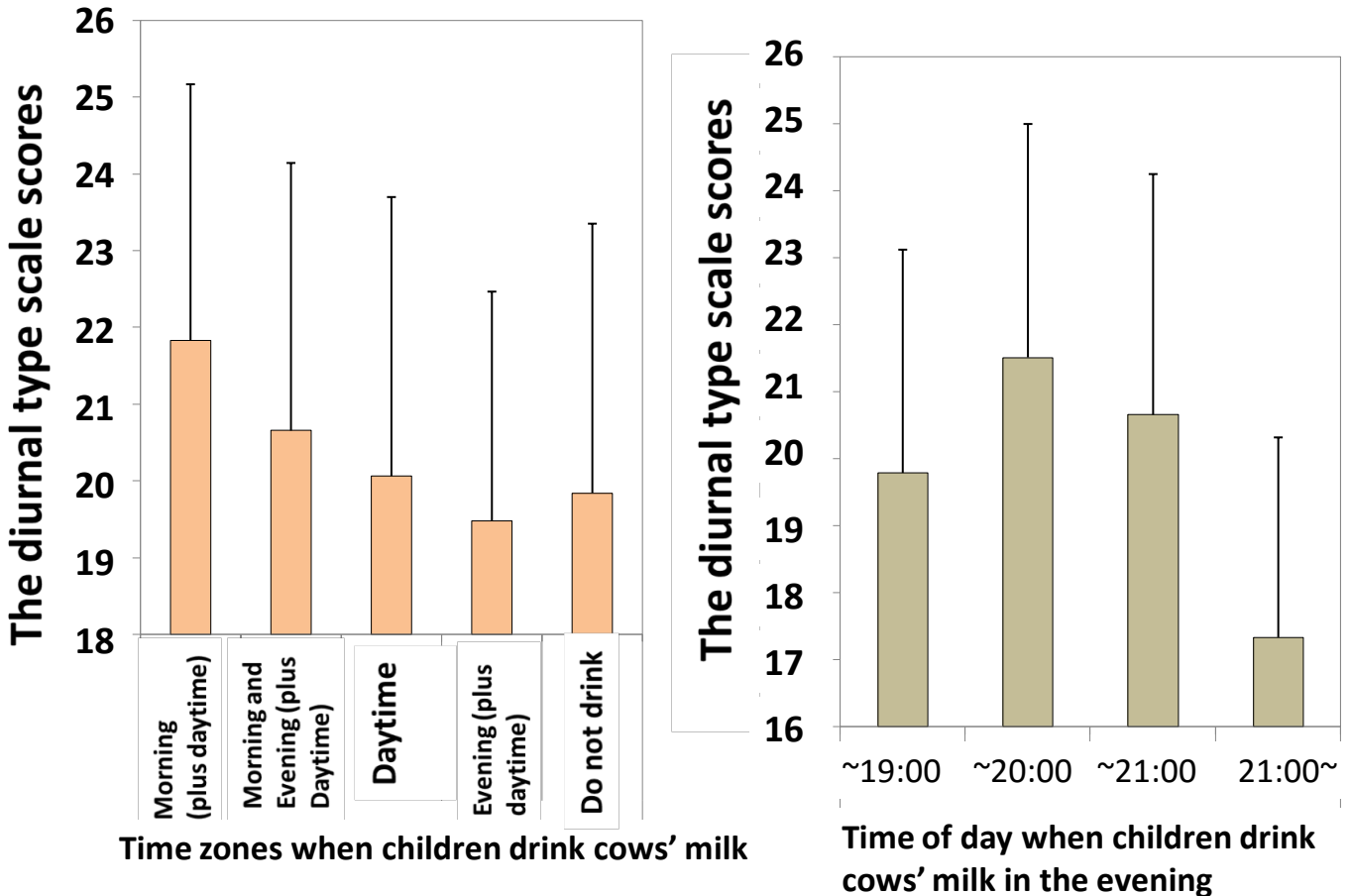

Figure 5. Relationship between time of day when small children drink cows' milk and the diurnal type scale. 

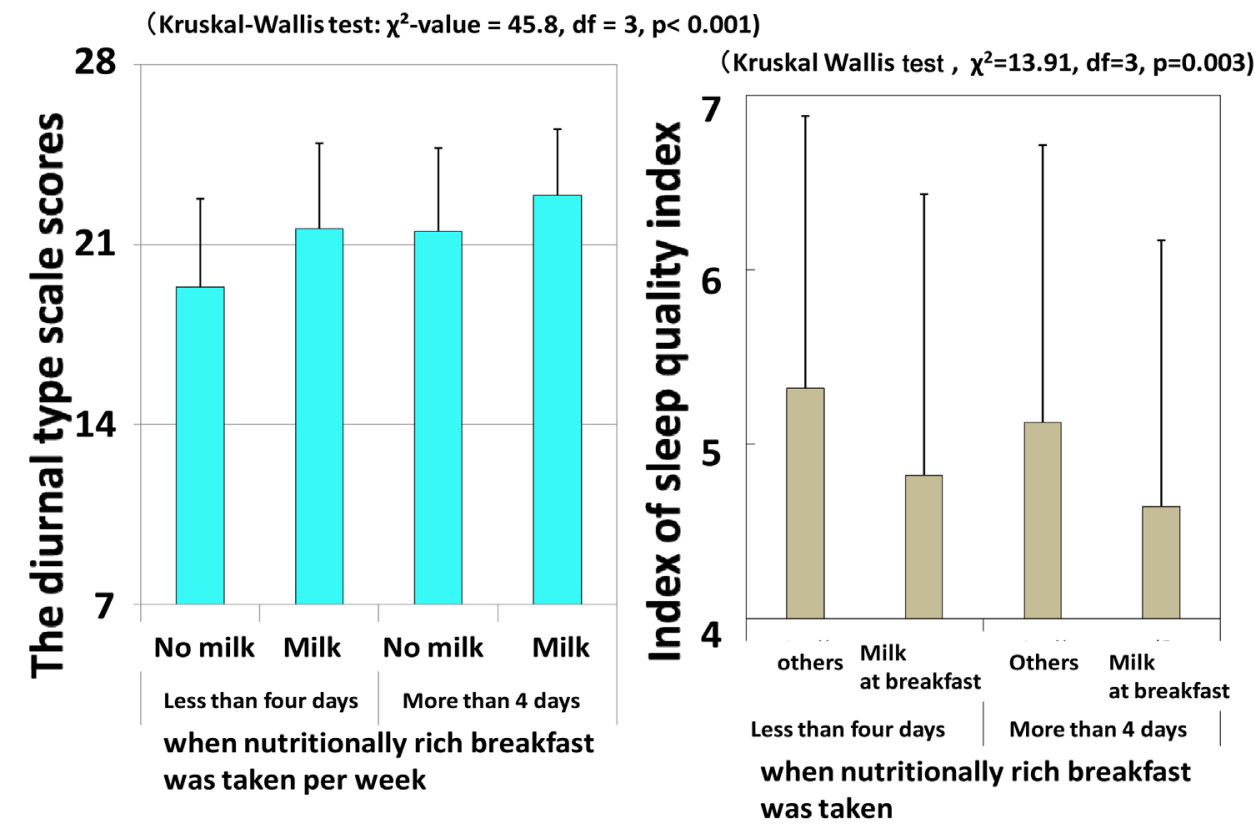

Figure 6. Relationship between whether Japanese children drink cows' milk at breakfast and nutritionally rich breakfast, and the diurnal type scale scores and sleep quality (lower scores with higher quality of sleep).

\subsection{An Intervention Study}

Children who drank cows' milk in 16 - 21 days during the 21 days intervention period occupied $67.2 \%$ of all participants (Figure $7(\mathrm{a})$ ). Sixty one percent and $64 \%$ of the children continued to drink cows' milk and also continued to take nutritionally rich breakfast currently even three months after the intervention period (Figure 7(b)). During the intervention 21 days and 3 months after that, 34 children (51.5\%) and 22 ones $(33.3 \%)$, respectively, of 66 participants increased the frequency to drink cows' milk in comparison with that at the beginning of intervention, whereas only 2 children (3.0\%) and 6 ones $(9.1 \%)$ decreased the frequency (Figure $7(\mathrm{c})$ ).

Twenty six children of 47 participants implemented one of two issues of "drinking cows' milk" and "taking nutritionally rich breakfast" through all the 21 interpretation days, whereas only five ones implemented both through the 21 days $\left(\chi^{2}\right.$-test, $\chi^{2}$ value $=$ $19.656, \mathrm{df}=1, p<0.001$ ) (Figure 8). Children who occupied $25 \%$ as morning-typed group were significantly shifted to more evening-typed after the 21 days intervention and the 3 months (Figure 9(a): Wilcoxon's test, $\mathrm{z}=-2.622, p=0.009$ ), whereas the other $75 \%$ as moderate and evening-typed group were significantly shifted to more morning-typed (Figure 9(a): Wilcoxon's test, $\mathrm{z}=-2.766, p=0.006$ ) (Figure 9(b): morning-type group versus the others, Mann-Whitney $\mathrm{U}$-test, $\mathrm{z}=-3.59, p<0.001)$.

Both in the morning-typed group and the other group, the frequency to be depressed 3 months after the intervention was significantly less than that before the intervention (Wilcoxon's test, all children: $\mathrm{z}=-3.879, p<0.001$; the morning-typed group: $\mathrm{z}=$ $-1.732, p=0.083$; the others: $\mathrm{z}=-3.358, p=0.001$ ) (Figure 10). There was positive correlation between the implementation days on which the children took a nutritionally 
(n)

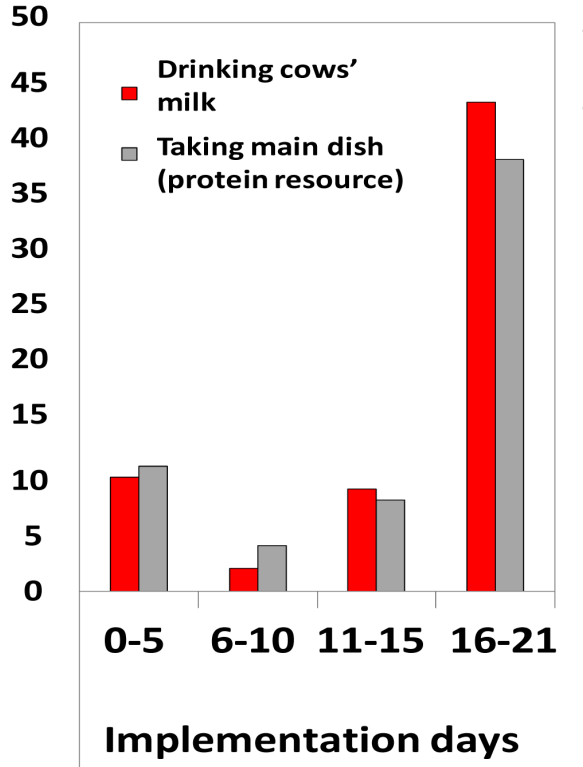

(n)

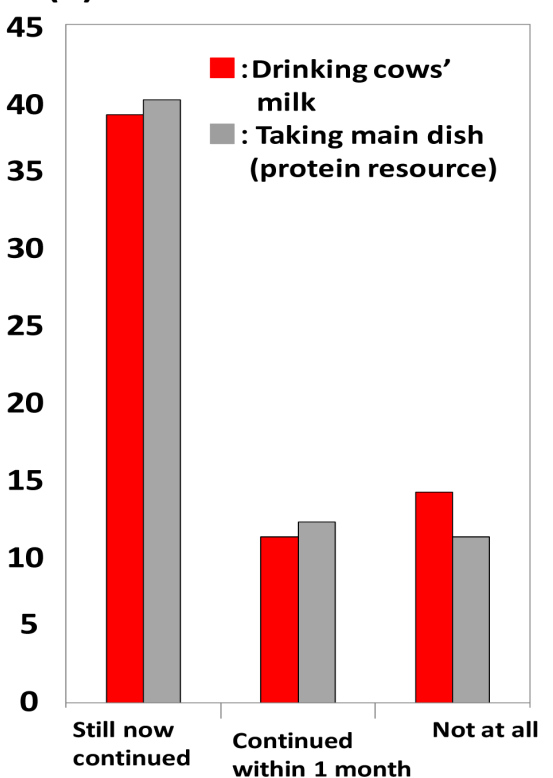

Whether implementation was continued after the intervention month
Change 1: "before" intervention versus intervention Period; Change 2: "before" intervention versus Three months after the intervention.

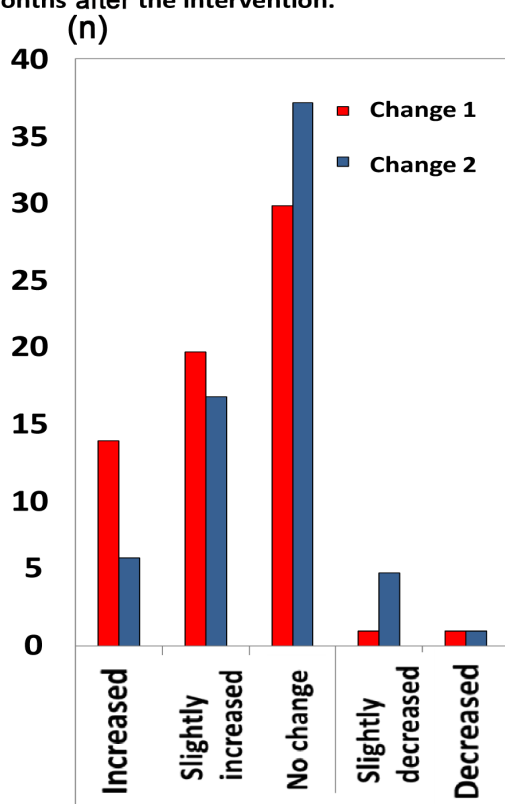

Frequency to drink cows' milk

Figure 7. Implementation days of drinking cows' milk for the three weeks intervention days and three weeks after the intervention 3 weeks in the Japanese small children attending a kindergarten.

(n)

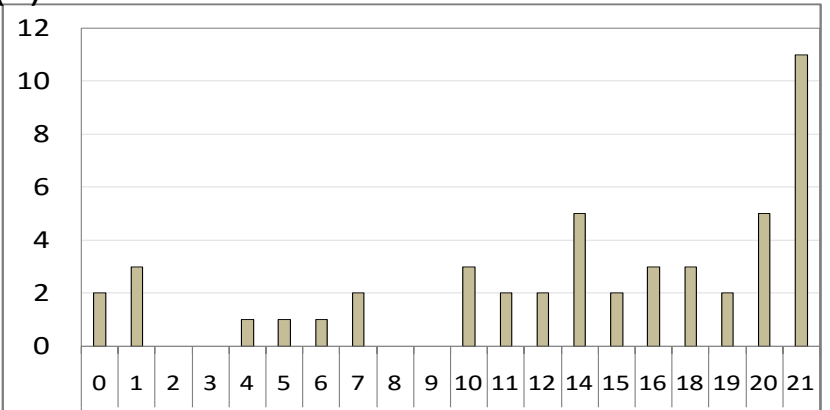

Implementation days (drinking milk at breakfast)

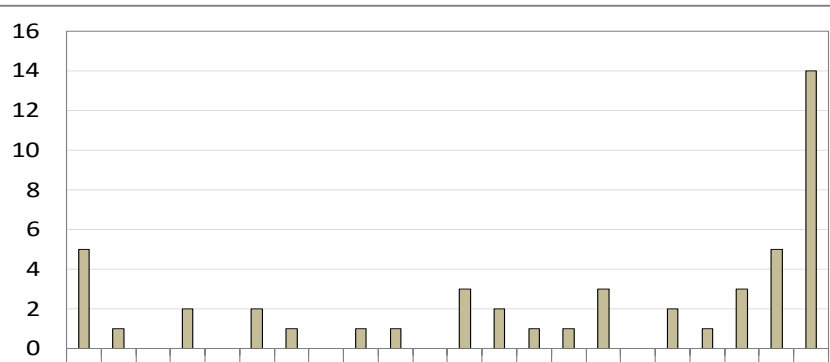

(n) 0 \begin{tabular}{lllllllllll|l|l} 
& 1 & 2 & 3 & 4 & 5 & 6 & 7 & 8 & 9 & 1011 & 12131415161718192021
\end{tabular}

Implementation days (main dish at breakfast)

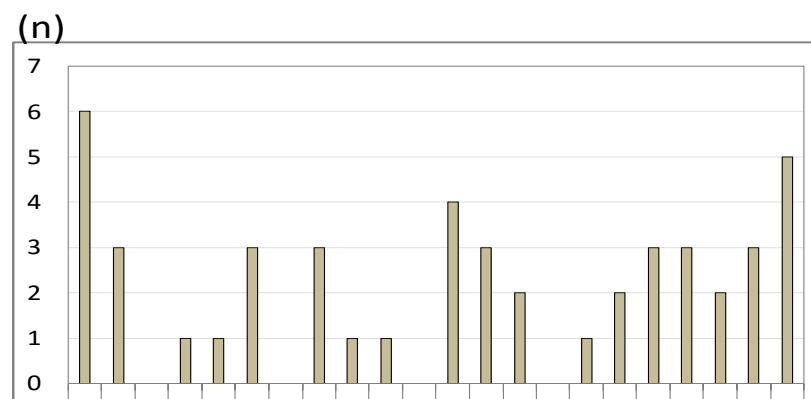

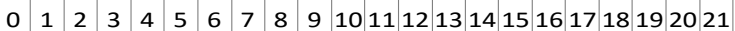
Implementation days (milk and main dish at breakfast)

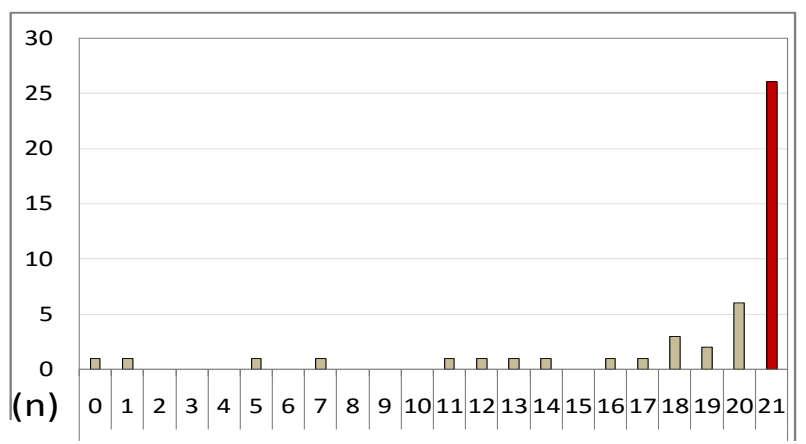

Implementation days (milk or main dish at breakfast)

Figure 8. Implementation days of drinking cows' milk and/or taking nutritional breakfast. 


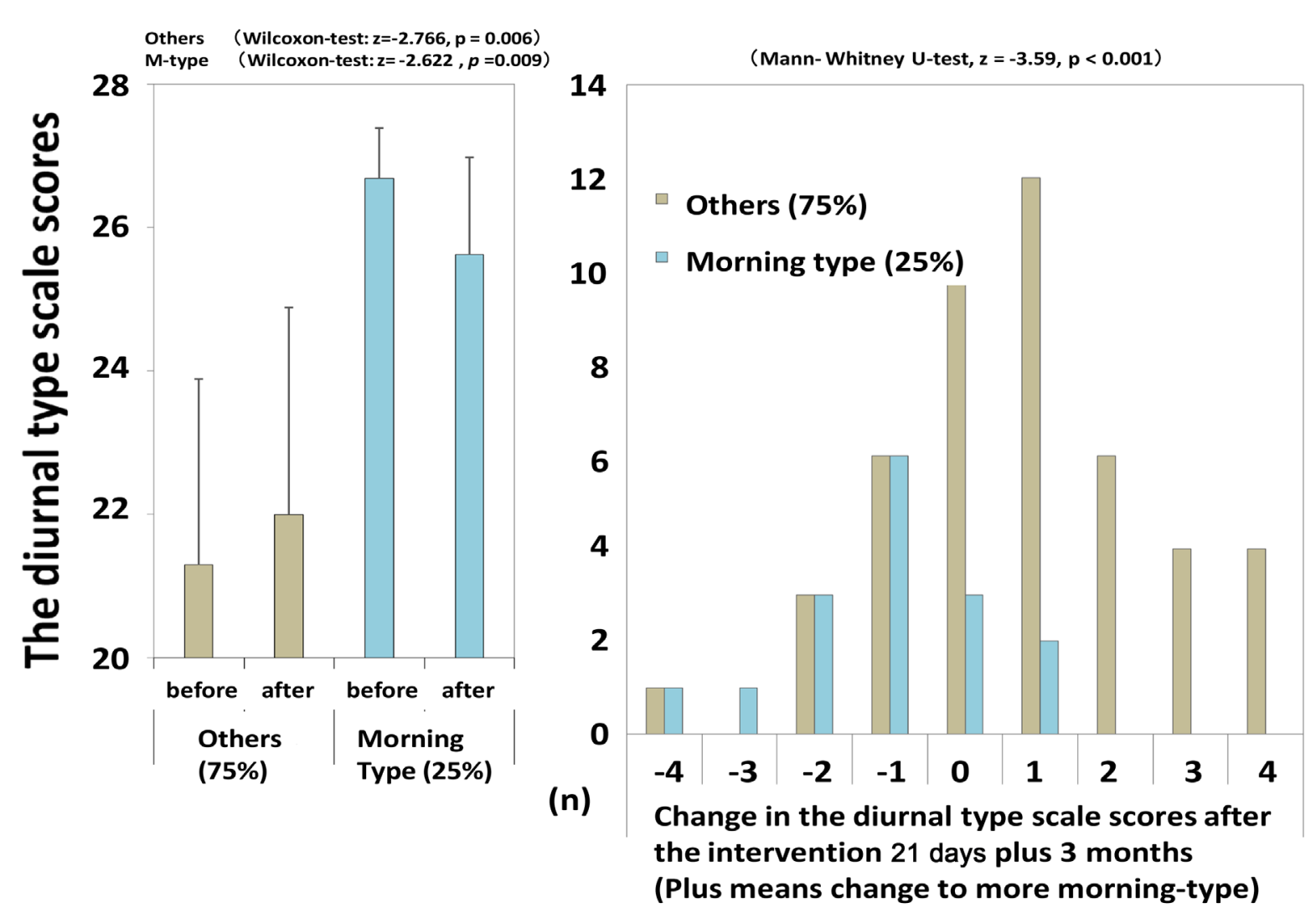

Figure 9. Change in the diurnal type scores before and after the intervention 3 weeks in Japanese kindergarten children.

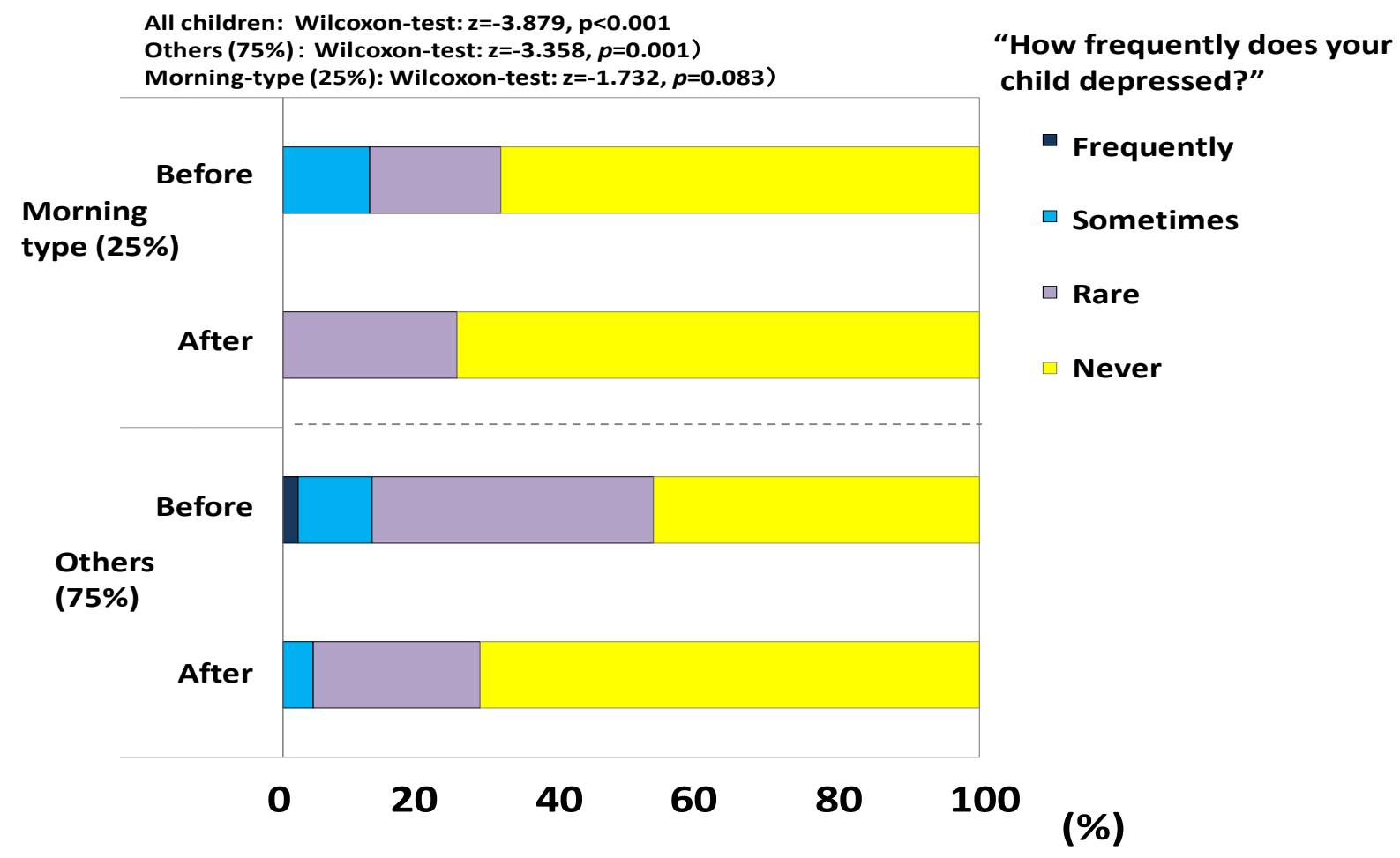

Figure 10. Change in the frequency of depression before and after the intervention three months. 
rich breakfast and also drank cows' milk at breakfast, and the diurnal type scale scores three months after the intervention (Pearson's correlation analysis: $\mathrm{r}=0.416, p<$ 0.001) (Figure 11).

Children who drank cows' milk on 4 - 9 days during the intervention 21 days shifted to more morning-typed 3 months after the intervention, whereas those who did it only 0 - 1 day shifted to more evening-typed (Mann-Whitney U-test: $\mathrm{z}=-2.353, p=0.017$ ) (Figure 12). More than $50 \%$ of children implemented 6 of 7 contents of the intervention on 11-15 days or more during the 21 days and also for 3 months after the intervention (Figure 13(a) and Figure 13(b)). However, only 20\% and 37\% of children implemented "No TV watching" on 11 - 15 days or more during the 21 days and also for 3 months after that, respectively (Figure 13(a) and Figure 13(b)). There were significantly positive correlations between the frequency of implementation of 7 contents during the 21 days (Pearson's test: $\mathrm{r}=0.301 p=0.018)$ and that during 3 months $(\mathrm{r}=$ $-0.421 p=0.002$ ) after the 21 days, and also the diurnal type scores (more morningtyped with more implementation: Figure 14).

\section{Discussion}

In the fundamental questionnaire study, the habit to drink cows' milk in the morning seems to occupy the majority of Japanese infants. This habit to drink it might be effective for them to be more morning-typed, have a better sleep health and also promote mental health based on this intervention study. Tryptophan included in cows' milk taken at breakfast would be effective on promoting better mental health and morning-typed life through serotonin and melatonin synthesis like as other protein resources of fermented soybeans, eggs, dried fishes, hams and so on [7]-[10]. Morning peak of

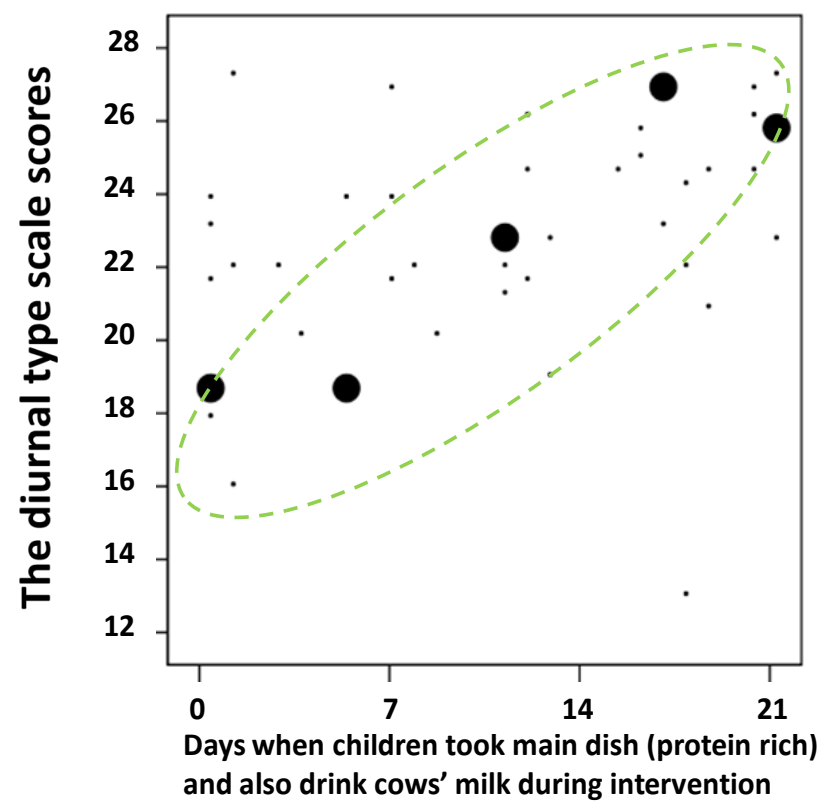

Figure 11. The diurnal type scale scores just after the intervention, and the implementation days to drink cows' milk at breakfast and also to take nutritionally rich breakfast for the 3 weeks. 


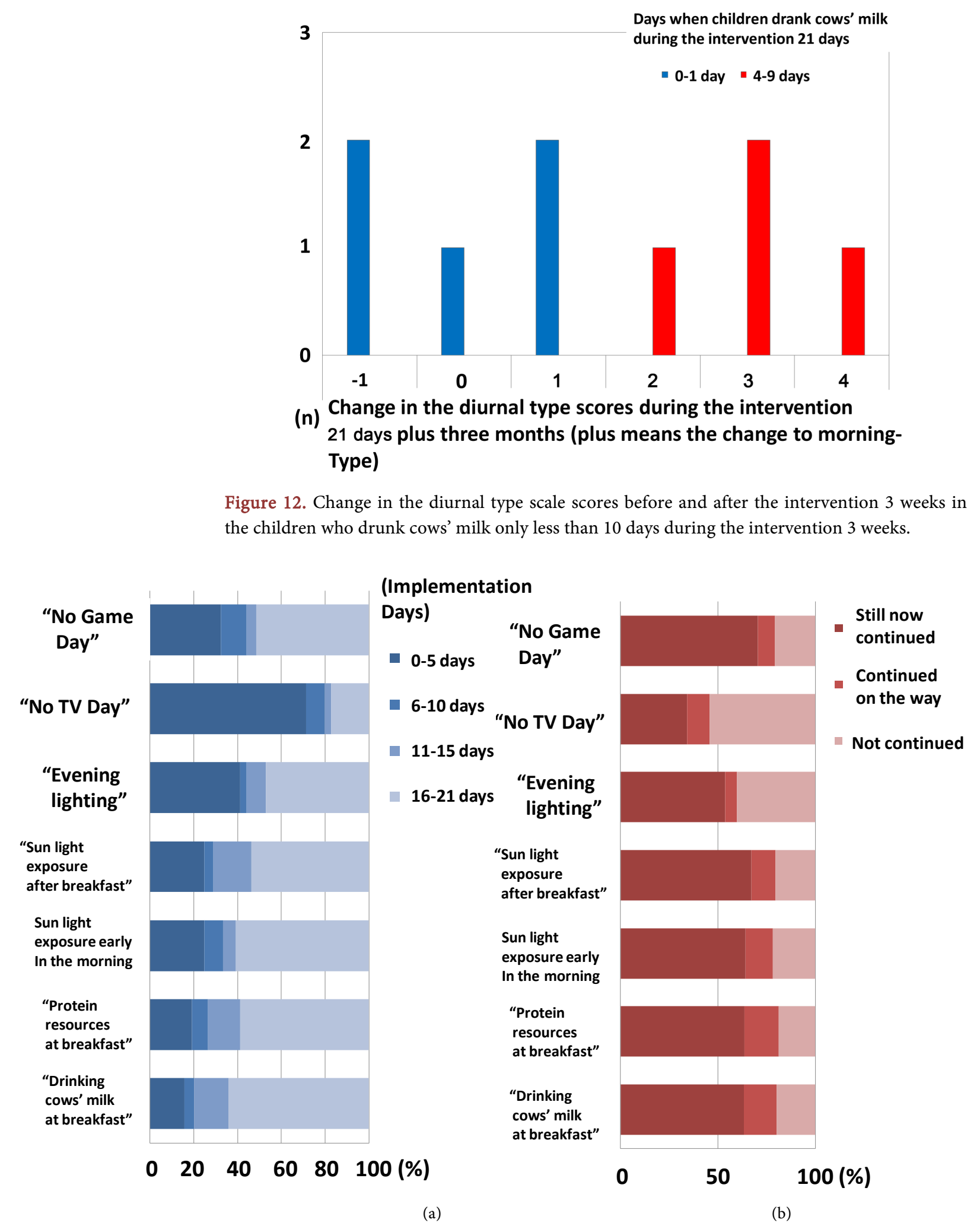

Figure 13. Implementation percent for the intervention 3 weeks (a) and 3 months after the intervention (b) on the contents of a leaflet "Let's make sure it because of drinking cows' milk at breakfast!" Three benefits of "Go to bed earlier! Get up earlier! and Taking nutritionally rich breakfast!" in Japanese Kindergarten children. 


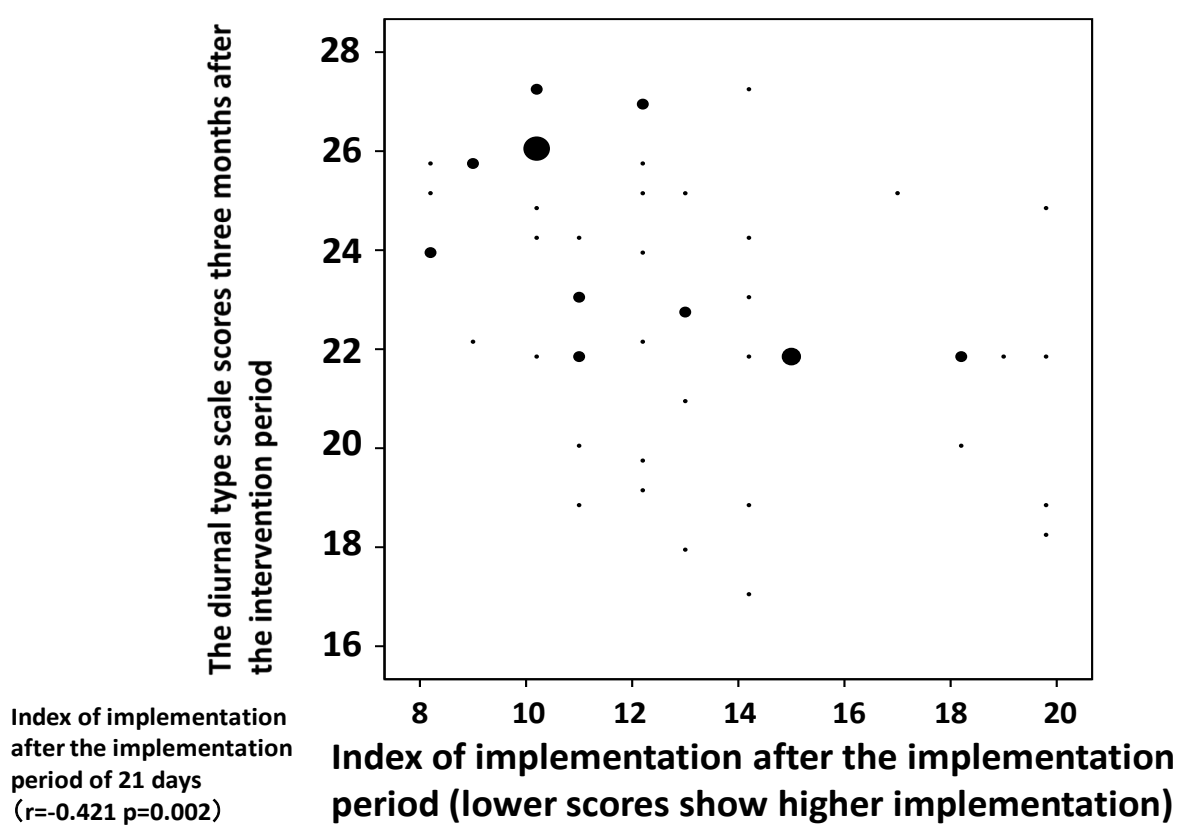

Figure 14. Relationship between the diurnal type of infants three months after the intervention 3 weeks, and index of the implementation of 7 issues of the leaflet during the 3 months after the intervention.

serotonin in cerebrospinal fluid and evening peak of plasma melatonin could be a zeitgeber for human circadian clock in suprachiasmaic nucleus (SCN) [14]. For Japanese children, cow milk can be important resource for taking tryptophan at breakfast because of limited meal time in the morning based on the result of this intervention study.

There have been intervention studies by Ishii et al. [15] [16] on promoting health of Japanese elementary school students with drinking cows' milk. Ishii et al. [16] reported that the after-school drinking of cows' milk enhanced the preference to take breakfast and lunch. Moreover, Ishii et al. [16] performed the intervention of inter-classes drinking cows' milk in the morning and it increased the concentration into classes after taking cow milk in comparison with the control group which has not drunk it.

Implementation of drinking cows' milk would be relatively easy, while that to watch no TV in the evening is difficult for Japanese infants. Watching TV for long-hours in the evening could make children evening-typed. The short-wave lights could impress the plasma melatonin in the evening, and melanopsin (peak wave length to absorve: $460 \mathrm{~nm}$ ) is key functional substance in neuroganglion cells in retina, to depress the melatonin [17] [18]. Intervention to recommend no-TV watching at night is important.

Nakagawa [19] reported that drinking cows' milk by Japanese infants could lead to increase an integrated health score which consists of four issues dealing with "catching cold", "attack of fever", "appetite level", "irritation and diarrhea". However, these physiological and psychological positive effects of drinking cows' milk did not mention about "circadian timing" of the milk supplement. This study implies that the "drinking by small children in the morning" of the cows' milk can make their circadian clocks be in phase-advance especially for "evening-typed" infants based on the intervention study 
at the first time.

\section{Conclusion}

In the questionnaire study, the Japanese infants who had drunk cows' milk every morning were significantly morning-typed than those who had not drunk it $(p=0.01)$. Drinking cows' milk at a breakfast seems to be effective for small children to become more morning-typed through two sets of syntheses from tryptophan via serotonin into melatonin in the evening.

\section{Acknowledgements}

We thank all the participants of this study. Thanks are also due to the financial supports by Research Foundation by Japan Dairy Association (J-MILK) (2013-2004, 20042015, 2015-2016) (To T. HARADA)

\section{References}

[1] Sánchez, C.L., Cubero, J., Sánchez, J., Chanclón, B., Rivero, M. and Barriga, C. (2009) The Possible Role of Human Milk Nucleotidesas Sleep Inducers. Nutritional Neuroscience, 12, 2-8. http://dx.doi.org/10.1179/147683009X388922

[2] Cubero, J., Valero, V., Sanchez, J., Rivero, M., Parvez, H., Rodriguez, A.B. and Barriga, C. (2005) The Circadian Rhythm of Tryptophan in Breast Milk Affects the Rhythms of 6-Sulfatoxymelatonin and Sleep in Newborn. Neuroendocrinology Letters, 26, 657-661.

[3] Laird, D.A. and Drexel, H. (1934) Experimenting with Food and Sleep. I. Effects of Varying Types of Foods in Offsetting Sleep Disturbances Caused by Hunger Pangs and Gastric Distress Children and Adults. Journal of American Dietetic Association, 10, 89-94.

[4] Brezinova, V. and Oswald, I. (1972) Sleep after a Bedtime beverage. British Medical Journal, 2,431-433. http://dx.doi.org/10.1136/bmj.2.5811.431

[5] Guesdon, B., Messaoudi, M., Lefranc-Millot, C., Fromentin, G., Tome, D. and Even, P.C. (2006) A Tryptic Hydrolysate from Bovine Milk aS1-Casein Improves Sleep in Rats Subjected to Chronic Mild Stress. Peptides, 27, 1476-1482. http://dx.doi.org/10.1016/j.peptides.2005.10.001

[6] Takeuchi, H., Wada, K., Kawasaki, K., Krejci, M., Noji, T., Kawada, T., Nakade, M. and Harada, T. (2014) Effects of Cow Milk Intake at Breakfast on the Circadian Typology and Mental Health of Japanese Infants Aged 1-6 Years. Psychology, 5, 172-176. http://dx.doi.org/10.4236/psych.2014.52027

[7] Harada, T., Hirotani, M., Maeda, M., Nomura, H. and Takeuchi, H. (2007) Correlation between Breakfast Tryptophan Content and Morningness-Eveningness in Japanese Infants and Students Aged 0-15 yrs. Journal of Physiological Anthropology, 26, 201-207. http://dx.doi.org/10.2114/jpa2.26.201

[8] Nakade, M., Takeuchi, H., Taniwaki, N., Noji, T. and Harada, T. (2009) An Integrated Effect of Protein Intake at Breakfast and Morning Exposure to Sunlight on the Circadian Typology in Japanese Infants Aged 2-6 Years. Journal of Physiological Anthropology, 28, 239-245. http://dx.doi.org/10.2114/jpa2.28.239

[9] Nakade, M., Akimitsu, O., Wada, K., Krejci, M., Noji, T., Taniwaki, N., Takeuchi, H. and Harada, T. (2012) Can Breakfast Tryptophan and Vitamin B6 Intake and Morning Exposure to Sunlight Promote Morning-Typology in Young Children Aged 2 to 6 Years? Journal of Physiological Anthropology, 31, 11. http://www.jphysiolanthropol.com/content/31/1/11 
http://dx.doi.org/10.1186/1880-6805-31-11

[10] Wada, K., Yata, S., Akimitsu, O., Krejci, M., Noji, T., Nakade, M., Takeuchi, H. and Harada, T. (2013) A Tryptophan-Rich Breakfast and Exposure to Light with Low Color Temperature at Night Improve Sleep and Salivary Melatonin Level in Japanese Students. Journal of Circadian Rhythms, 11, 4. http://dx.doi.org/10.1186/1740-3391-11-4

[11] Torsvall, M.D. and Åkerstedt, T.A. (1980) A Diurnal Type Scale: Construction, Consistency and Validation in Shift Work. Scandinavian Journal of Work \& Environmental Health, 6, 283-290. http://dx.doi.org/10.5271/sjweh.2608

[12] Horne, J.A. and Östberg, O. (1976) A Self Assessment Questionnaire to Determine Morningness-Eveningness in Human Circadian Rhythm. Chronobiology International, 4, 97 110.

[13] Portaluppi, F., Smolensky, M.H. and Touitou, Y. (2010) Effects and Methods for Biological Rhythm Research on Animals and Human Beings. Chronobiology International, 27, 19111929. http://dx.doi.org/10.3109/07420528.2010.516381

[14] Svobodova, I., Vanecek, J. and Zemkova, H. (2003) The Bidirectional Phase-Shifting Effects of Melatonin on the Arginine Vasopressin Secretion Rhythm in Rat Suprachiasmatic Nuclei in Vitro. Molecular Brain Research, 116, 80-85. http://dx.doi.org/10.1016/S0169-328X(03)00254-7

[15] Ishii, M., Yano, H. and Suzuki, E. (2011) Evaluating the New Method of Milk-Supply on the Interval of Morning-Classes in Elementary School. Bulletin of Faculty of Home Economy, Otsuma Women's University, 47, 27-37.

[16] Ishii, M., Yano, H. and Suzuki, E. (2012) Evaluating the New Method of Milk-Supply on the After-School Class in Elementary School. Bulletin of Faculty of Home Economy, Otsuma Women's University, 48, 47-56.

[17] Morgia, C.L., Ross-Cisnerosm, F.N., Hannibal, J., Montagna, P., Sadun, A.A. and Carelli, V. (2011) Melanopsin-Expressing Retinal Ganglion Cells: Implications for Human Diseases. Vision Research, 51, 296-302. http://dx.doi.org/10.1016/j.visres.2010.07.023

[18] Takeuchi, U., Imamura, S., Sawada, Y., Hut, S.-P. and Takemura, A. (2014) Effects of Different Colors of Light on Melatonin Suppression and Expression Analysis of Aanat1 and Melanopsin in the Eye of a Tropical Damselfish. General and Comparative Endocrinology, 204, 158-165. http://dx.doi.org/10.1016/j.ygcen.2014.05.015

[19] Nakagawa, Y. (1991) Relationship between Health Conditions and Dietary Habit of PreSchool Children: Study on Breakfast and Between-Meal Snacks. The Japanese Journal of Nutrition and Dietetics, 49, 81-90. (In Japanese) http://dx.doi.org/10.5264/eiyogakuzashi.49.81 
Submit or recommend next manuscript to SCIRP and we will provide best service for you:

Accepting pre-submission inquiries through Email, Facebook, LinkedIn, Twitter, etc. A wide selection of journals (inclusive of 9 subjects, more than 200 journals)

Providing 24-hour high-quality service

User-friendly online submission system

Fair and swift peer-review system

Efficient typesetting and proofreading procedure

Display of the result of downloads and visits, as well as the number of cited articles

Maximum dissemination of your research work

Submit your manuscript at: http://papersubmission.scirp.org/ 